\title{
Virtual Screening of CDK9 Inhibitors as Potential Anti Cancer Drugs
}

\author{
Ravi Kumar K. \\ Centre for Biotechnology \\ Jawaharlal Nehru \\ Technological University, \\ Hyderabad, India.
}

\author{
Archana Giri \\ Centre for Biotechnology \\ Jawaharlal Nehru \\ Technological University \\ Hyderabad, India.
}

\author{
Rama Rao Nadendla \\ Chalapathi Institute Of \\ Pharmaceutical Sciences \\ Guntur, India.
}

\begin{abstract}
Cell cycle inhibition is important hallmark of anti cancer research. CDKs are divided into two types based on their Cell cycle controlling and transcriptional control. CDK 9, a transcriptional regulator serves as potential drug target. Only few drugs are under clinical trials phase $1 / 2 / 3$ of CDK 9 inhibitory potential. 3BLR (pdb id) is used as docking target. Virtual screening is carried out based on the pharmacophore information generated from literature. Docking is carried out using Molegro virtual docker with all the compounds and top ranking compounds are shortlisted. The best compound (ZINC91643349) was identified and further analyzed by Invitro assays.
\end{abstract}

\section{Keywords}

CDK9, CDK9 inhibitors, Virtual Screening, Molecular Docking

\section{INTRODUCTION}

Regulation of cell cycle forms the key event in cell growth and division which maintains optimal cell volume in a tissue at the physiological states. Dysregulation of genes involved in cell cycle regulation can lead to abnormal cell division which is otherwise manifested as cancer. ${ }^{[1,2,3]}$ Cyclin and cyclin-dependent kinases are family of evolutionary conserved serine/threonine kinases that are modular components of the core clock machinery of the cell cycle. ${ }^{[4]}$ In each phase of the cell cycle, CDK phosphorylates distinct proteins and regulate the cell cycle. Deregulation of cyclins, alterations or absence of CDK inhibitors can disturb the cell cycle regulation resulting in tumor formation.

In addition to its crucial role in cell cycle regulation, CDKs also participate in physiological process such as neuronal function and forms an important protein in transcription machinery. CDKs can generally be classified into two major groups. ${ }^{[5-6]}$ Type 1 include CDK1 to CDK6 that control the cell cycle progression, whereas Type 2 group includes CDK8, CDK9, CDK12 and CDK19 which are linked to gene transcription regulation by RNA polymerase II. $^{[7]} \mathrm{CDK} 7$ and
CDK20 act in both cell cycle control and transcription processes. Several CDKs (such as CDK10, CDK11A, CDK11B, CDK13) are involved in RNA processing. ${ }^{[8]}$ CDK9 is a catalytic subunit of positive transcription elongation factor activated by either cyclin T or K. CDK9/T1 complex are highly expressed in nuero ectodermal and nueroblastoma tumors. ${ }^{[9]}$

CDKs does not operate in isolation, a synergistic association with proteins called cyclins, catalyses the kinase activity of CDKs. After the association with cyclin, CDKs result in stimulating the transcription elongation of RNA pol II enzyme. The inhibitors of CDK9 are under clinical trials and some of them have entered phase 2 or phase 3 , while some of the inhibitors have been now approved by FDA, nevertheless, still raises high concerns of hypersensitivity. ${ }^{[10]}$ Hence the present study pursues to identify potential CDK9 inhibitors through high throughput virtual screening approaches.

\section{METHODOLOGY}

\subsection{Preparation of Protein}

The crystal Structure of Human CDK9/cyclinT1 in complex with Flavopiridol was retrieved with PDB ID: 3BLR.[11,12] The X-Ray diffraction structure of CDK9 receptor had a resolution of $2.8 \AA, \mathrm{R}$ value of 0.176 and $\mathrm{R}$ free value of 0.228 unit cells.

\subsection{Dataset Selection}

Derivatives of 2-anilino-4-(thiazol-5-yl) pyrimidine transcriptional CDK inhibitors [Table1] are used in the current study.[13] Derivatives of N-phenyl-imidazo[4,5-b] pyridin-2amines, 4-indazolyl-N-phenylpyrimidin-2-amines and $\mathrm{N}$ phenyl-4-pyrazolo[3,4-b] pyridin-pyrimidin-2-amines [Table2] were used as potent anti-proliferative and CDK9 inhibitory activities in the present study.[14] Table 3 identifies the evaluated ADME physico chemical properties of all ligands under study. The property of each ligand was calculated in order to identify any ligand violating Lipinski rule of 5.[15] Based on these parameters the rule for searching of inhibitors from zinc databases has been designed.[16] 
Table 1. Structure Of Ligands Selected For Study With Activity Data

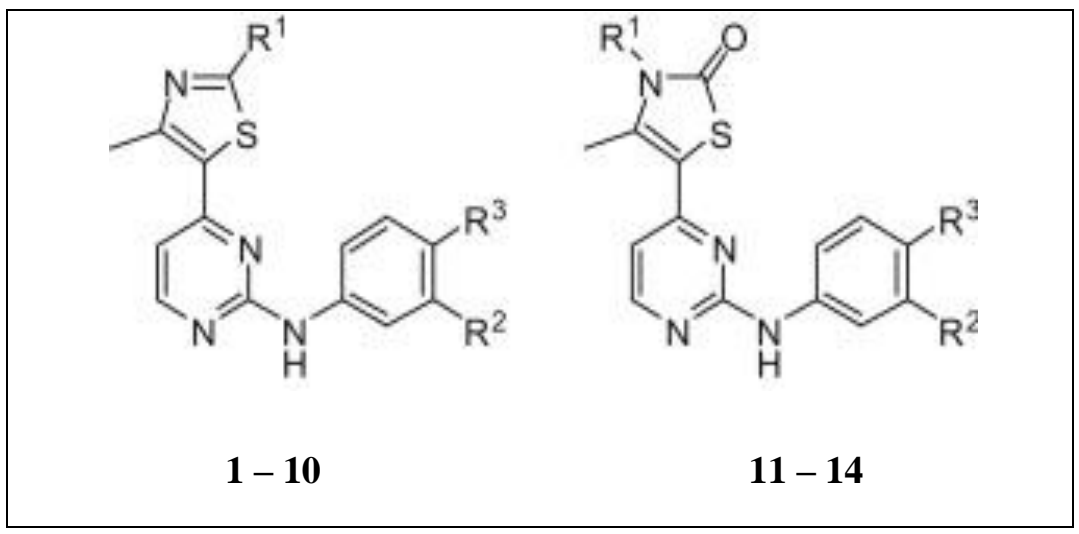

\begin{tabular}{|c|c|c|c|c|}
\hline Comp id & $\mathbf{R}^{1}$ & $\mathbf{R}^{2}$ & $\mathbf{R}^{3}$ & CDK9 activity (Ki, nM) \\
\hline 1 & $\mathrm{NH}_{2}$ & $\mathrm{NO}_{2}$ & $\mathrm{H}$ & 4.6 \\
\hline 2 & NHEt & $\mathrm{SO}_{2} \mathrm{NH}_{2}$ & $\mathrm{H}$ & 4.5 \\
\hline 3 & NHMe & $\mathrm{SO}_{2} \mathrm{NH}_{2}$ & $\mathrm{H}$ & 0.80 \\
\hline 4 & NHMe & $\mathrm{SO}_{2} \mathrm{NHMe}$ & $\mathrm{H}$ & 4.3 \\
\hline 5 & $\mathrm{NH}_{2}$ & $\mathrm{SO}_{2} \mathrm{NHMe}$ & $\mathrm{H}$ & 4.3 \\
\hline 6 & NHMe & $\mathrm{SO}_{2} \mathrm{Me}$ & $\mathrm{H}$ & 0.29 \\
\hline 7 & NHEt & $\mathrm{SO}_{2} \mathrm{Me}$ & $\mathrm{H}$ & 0.96 \\
\hline 8 & $\mathrm{NH}_{2}$ & $\mathrm{SO}_{2} \mathrm{NHEt}$ & $\mathrm{H}$ & 5.9 \\
\hline 9 & NHMe & $\mathrm{SO}_{2}$-morpholine & $\mathrm{Me}$ & 6.7 \\
\hline 10 & $\mathrm{NH}_{2}$ & $\mathrm{SO}_{2}$-morpholine & $\mathrm{Me}$ & 8.5 \\
\hline 11 & $\mathrm{Me}$ & $\mathrm{H}$ & $\mathrm{SO}_{2} \mathrm{NH}\left(\mathrm{CH}_{2}\right)_{2} \mathrm{OMe}$ & 14 \\
\hline 12 & $\mathrm{Me}$ & $\mathrm{CN}$ & $\mathrm{H}$ & 1.9 \\
\hline 13 & $\mathrm{Me}$ & $\mathrm{NO}_{2}$ & $\mathrm{Me}$ & 5.9 \\
\hline 14 & $\mathrm{Me}$ & $\mathrm{H}$ & Piperazine & 0.38 \\
\hline
\end{tabular}


Table 2: Structure Of Ligands Selected For Study With Activity Data.<smiles>[R][R]n1nc(-c2ccnc(Nc3ccccc3)n2)c2ccccc21</smiles>

$14 \mathrm{i}-\mathrm{u}$<smiles></smiles>

$18 a-18 b$

\begin{tabular}{|c|c|c|c|c|}
\hline Compound id & $\mathbf{R}^{1}$ & $\mathbf{R}$ & $\mathbf{X}^{1}$ & CDK9 activity (Ki, uM) \\
\hline $14 \mathrm{i}$ & $\mathrm{Me}$ & $\mathrm{p}-\mathrm{SO}_{2} \mathrm{NH}_{2}$ & - & 0.140 \\
\hline $14 \mathrm{j}$ & $\mathrm{Me}$ & $\mathrm{m}-\mathrm{SO}_{2} \mathrm{NH}_{2}$ & - & 0.098 \\
\hline $14 \mathrm{k}$ & Et & $\mathrm{p}-\mathrm{SO}_{2} \mathrm{NH}_{2}$ & - & 0.253 \\
\hline 141 & Et & $\mathrm{m}-\mathrm{SO}_{2} \mathrm{NH}_{2}$ & - & 0.154 \\
\hline $14 \mathrm{r}$ & n-Pr & $\mathrm{p}-\mathrm{SO}_{2} \mathrm{NH}_{2}$ & - & 0.176 \\
\hline $14 \mathrm{~s}$ & n-Pr & $\mathrm{m}-\mathrm{SO}_{2} \mathrm{NH}_{2}$ & - & 0.285 \\
\hline \multirow[t]{2}{*}{$14 \mathrm{t}$} & 3-methyl & $\mathrm{p}-\mathrm{SO}_{2} \mathrm{NH}_{2}$ & - & 0.207 \\
\hline & Pyridine & & & \\
\hline \multirow[t]{2}{*}{$14 u$} & 3-methyl & $\mathrm{m}-\mathrm{SO}_{2} \mathrm{NH}_{2}$ & - & 0.314 \\
\hline & Pyridine & & & \\
\hline $18 \mathrm{a}$ & $\mathrm{H}$ & $\mathrm{p}-\mathrm{SO}_{2} \mathrm{NH}_{2}$ & $\mathrm{CH}$ & 0.091 \\
\hline $18 \mathrm{~b}$ & $\mathrm{H}$ & $\mathrm{m}-\mathrm{SO}_{2} \mathrm{NH}_{2}$ & $\mathrm{CH}$ & 0.017 \\
\hline
\end{tabular}

Table 3. Lipinski Compliant Data Of Ligands Under Study.

\begin{tabular}{llllll}
\hline Molecule id & Mol. Weight & $\begin{array}{l}\text { H-bond } \\
\text { acceptors }\end{array}$ & $\begin{array}{l}\text { H-bond } \\
\text { Donors }\end{array}$ & LogP & $\begin{array}{l}\text { Rotatable } \\
\text { Bonds }\end{array}$ \\
\hline 1 & 328.38 & 5 & 2 & 2.5096 & 3 \\
2 & 390.52 & 5 & 3 & 1.632 & 6 \\
3 & 376.49 & 5 & 3 & 1.2895 & 5 \\
4 & 390.52 & 5 & 3 & 1.536 & 6 \\
5 & 376.49 & 5 & 3 & 1.3222 & 5 \\
6 & 375.5 & 5 & 2 & 1.9148 & 5 \\
7 & 389.53 & 5 & 2 & 2.2573 & 6
\end{tabular}




\begin{tabular}{|c|c|c|c|c|c|}
\hline 8 & 390.52 & 5 & 3 & 1.6647 & 6 \\
\hline 9 & 460.62 & 7 & 2 & 1.9071 & 6 \\
\hline 10 & 446.59 & 7 & 2 & 1.6933 & 5 \\
\hline 11 & 435.56 & 6 & 2 & -0.2929 & 8 \\
\hline 12 & 323.4 & 4 & 1 & 0.970701 & 3 \\
\hline 13 & 357.42 & 5 & 1 & 1.5265 & 3 \\
\hline 14 & 382.53 & 4 & 2 & 0.337601 & 4 \\
\hline $14 \mathrm{i}$ & 380.46 & 5 & 2 & 2.0486 & 4 \\
\hline $14 j$ & 380.46 & 5 & 2 & 2.0486 & 4 \\
\hline $14 \mathrm{k}$ & 394.49 & 5 & 2 & 2.3911 & 5 \\
\hline 141 & 394.49 & 5 & 2 & 2.3911 & 5 \\
\hline $14 \mathrm{r}$ & 408.52 & 5 & 2 & 2.8597 & 6 \\
\hline $14 \mathrm{~s}$ & 408.52 & 5 & 2 & 2.8597 & 6 \\
\hline $14 \mathrm{t}$ & 458.56 & 5 & 2 & 3.7949 & 5 \\
\hline $14 u$ & 458.56 & 5 & 2 & 3.7949 & 5 \\
\hline $18 \mathrm{a}$ & 366.43 & 5 & 2 & 1.9463 & 4 \\
\hline $18 b$ & 366.43 & 5 & 2 & 1.9463 & 4 \\
\hline
\end{tabular}

\subsection{High throughput virtual screening}

From the CDK-9 inhibitors reported in literature, a preliminary docking analysis was carried out using Molegro Virtual Docker ${ }^{[17-18]}$ to assess the inhibitory characteristics of literature compounds against $3 \mathrm{BLR}$ and found that these compounds shared similar geometric orientations within the active site region of CDK-9. Hence, as given in table-3, the physico-chemical features of all 24 compounds were evaluated using Tsar Software ${ }^{[19]}$. An average of all the properties possessed by compounds are calculated and submitted to search ZINC database as lower limits with a maximum value being represented by Lipinski rule of 5 .

Table4: Lipinski rule of 5 and search criteria used for Virtual screening of the compounds.

\begin{tabular}{lllll}
\hline \multicolumn{2}{l}{ Lipinski rule of $\mathbf{5}$} & \multicolumn{4}{l}{ Search Criteria } \\
\hline a. $\quad$ Log $\mathrm{p}$ & $<5$ & a. & Log $\mathrm{p}$ & $2-5$ \\
b. Molecular wt. & $<500$ & b. & molecular wt. & $393-500$ \\
c. Rotatable bond & $<10$ & c. & Rotatable bonds & $5-10$ \\
d. Hydrogen bond acceptors & $<10$ & d. & $\begin{array}{l}\text { Hydrogen bond } \\
\text { acceptors }\end{array}$ & $5-10$ \\
e. Hydrogen bond donors & $<5$ & e. & $\begin{array}{l}\text { Hydrogen bond } \\
\text { donors }\end{array}$ & $2-5$ \\
\hline
\end{tabular}


Table 5: Top 10 Compounds Obtained From Virtual Screening

\begin{tabular}{|c|c|c|c|c|c|c|}
\hline \multicolumn{7}{|l|}{ Sl } \\
\hline No. & Ligand & MolDock Score & Rerank Score & HBond & MW & Docking Score \\
\hline 1 & ZINC91643349 & -186.47 & -138.578 & -6.98346 & 393.411 & -184.062 \\
\hline 2 & ZINC91643350 & -169.115 & -131.57 & -2.40923 & 393.411 & -166.762 \\
\hline 3 & ZINC98041458 & -177.427 & -131.268 & -6.47588 & 393.396 & -176.476 \\
\hline 4 & ZINC36273796 & -164.58 & -129.39 & -3.97439 & 392.408 & -165.082 \\
\hline 5 & ZINC98041458 & -160.436 & -128.758 & -9.10346 & 393.396 & -159.921 \\
\hline 6 & ZINC72426285_1 & -157.473 & -127.571 & -6.4537 & 394.381 & -160.483 \\
\hline 7 & ZINC27497243 & -168.444 & -127.284 & -5.57142 & 394.404 & -166.865 \\
\hline 8 & ZINC98248589_1 & -169.366 & -127.125 & -5.33789 & 394.404 & -165.457 \\
\hline 9 & ZINC21782806 & -176.682 & -126.763 & -5.17722 & 393.436 & -175.895 \\
\hline 10 & ZINC15920964 & -171.832 & -126.599 & -4.86656 & 393.436 & -170.056 \\
\hline
\end{tabular}

\section{RESULTS \& DISCUSSION}

The above search criteria resulted in 5991 ligands from Zinc database and all the compounds are docked with adjusted docking parameters [supplementary material 1]

1] Top best 100 molecules were discussed in [supplementary material 2]

2] Top 10 effective compounds results were studied [table 5].
Zinc database compound id: ZINC91643349, N-[(3S)-3-(4fluorophenyl)-3-(2-furyl)propyl]-3-(5-methyl-2-furyl)-1Hpyrazole-5-carboxamide found to be the best interacting with CDK9. Aromatic, Electrostatic, Hydrophobic, H-bond interactions were discussed for the best compound. [fig 3, 4, $5,6]$.

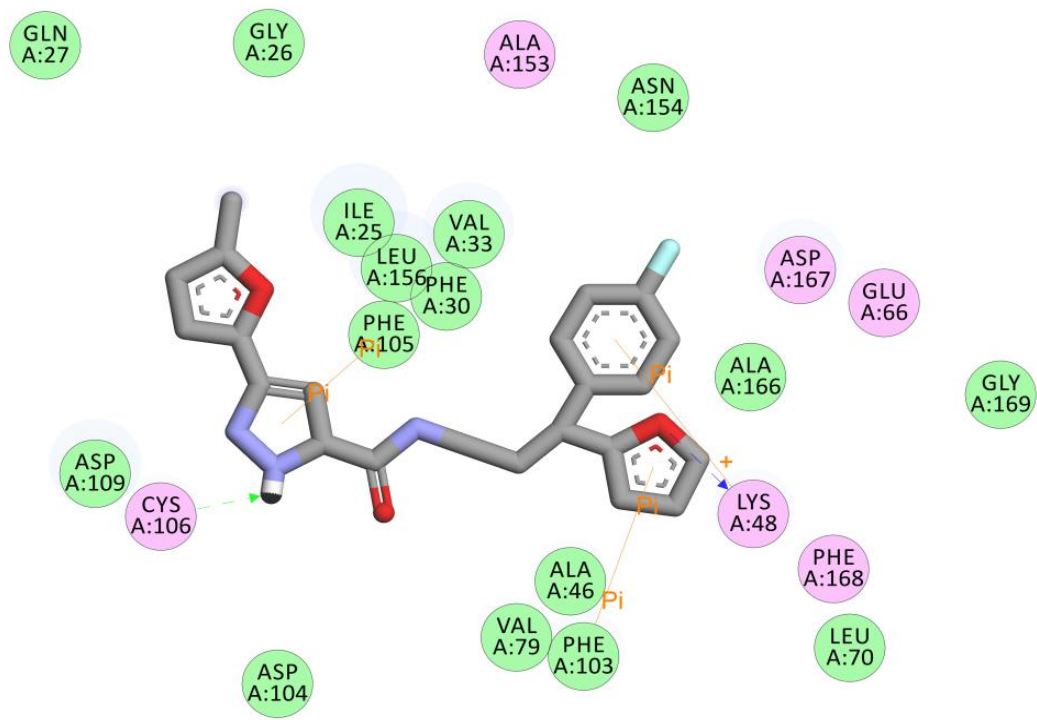

Fig 3: Interactions of ZINC91643349 in the cavity of CDK 9. Residues circled in green participate in van der Waals interaction while residues in pink forms electrostatic interactions. Hydrogen bond acceptors are shown in green color. 


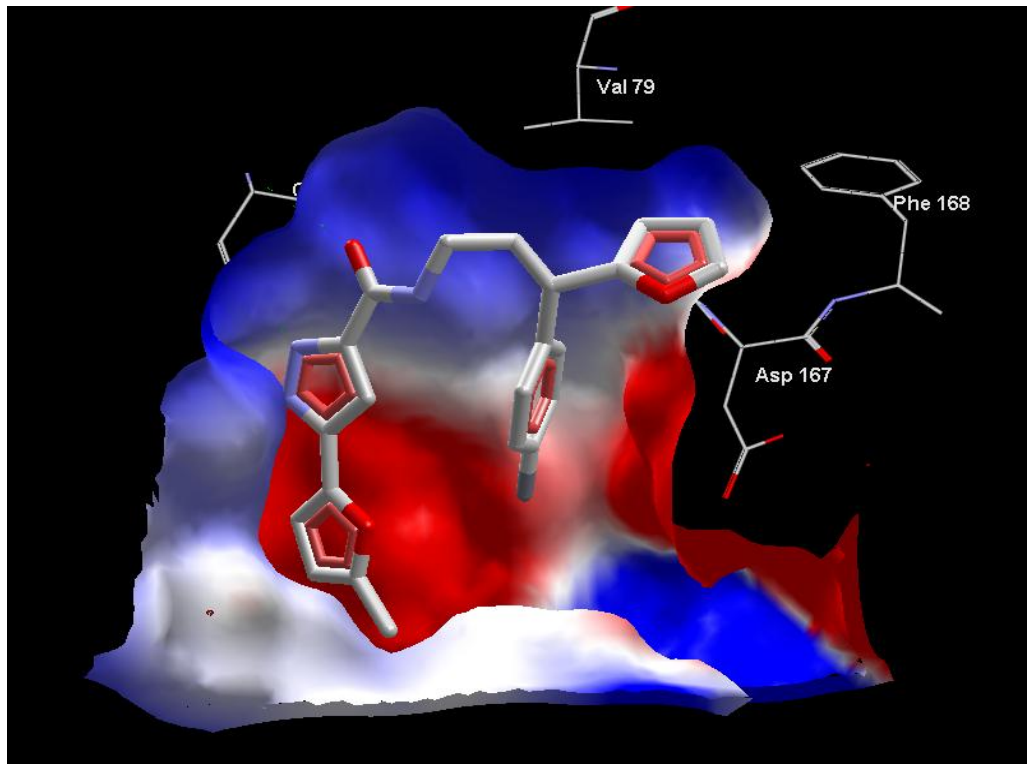

Fig 4: Electrostatic Interactions of ZINC91643349 in the active site of CDK 9. Electronegative surfaces are in red, while electropositive surfaces are blue. White is electrically neutral.

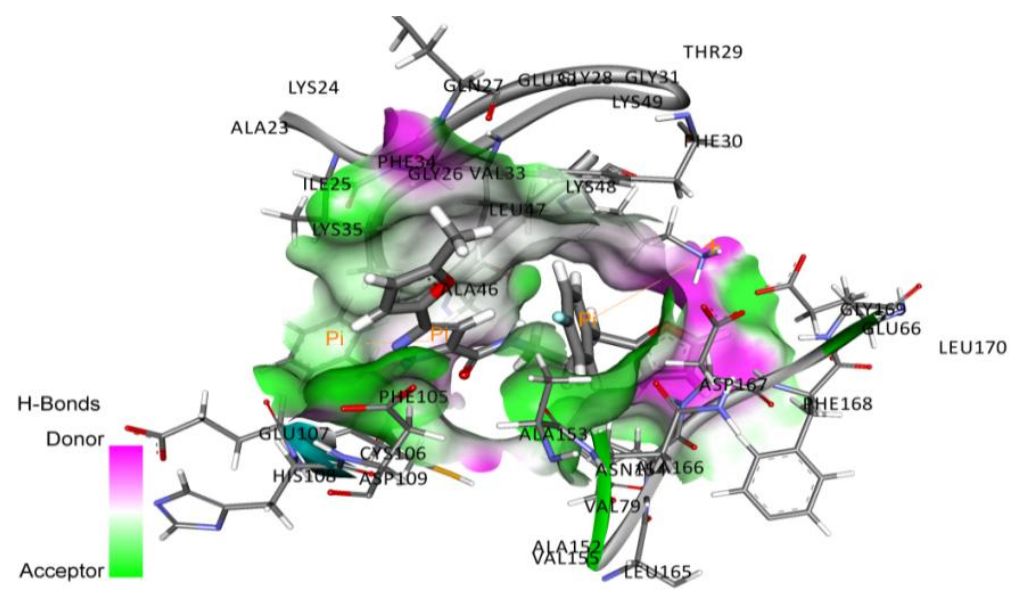

Fig 5: Interactions of ZINC91643349 in the cavity of CDK 9 with hydrogen bonding surface. Hydrogen bond donor surfaces are in pink, while acceptor surfaces are green

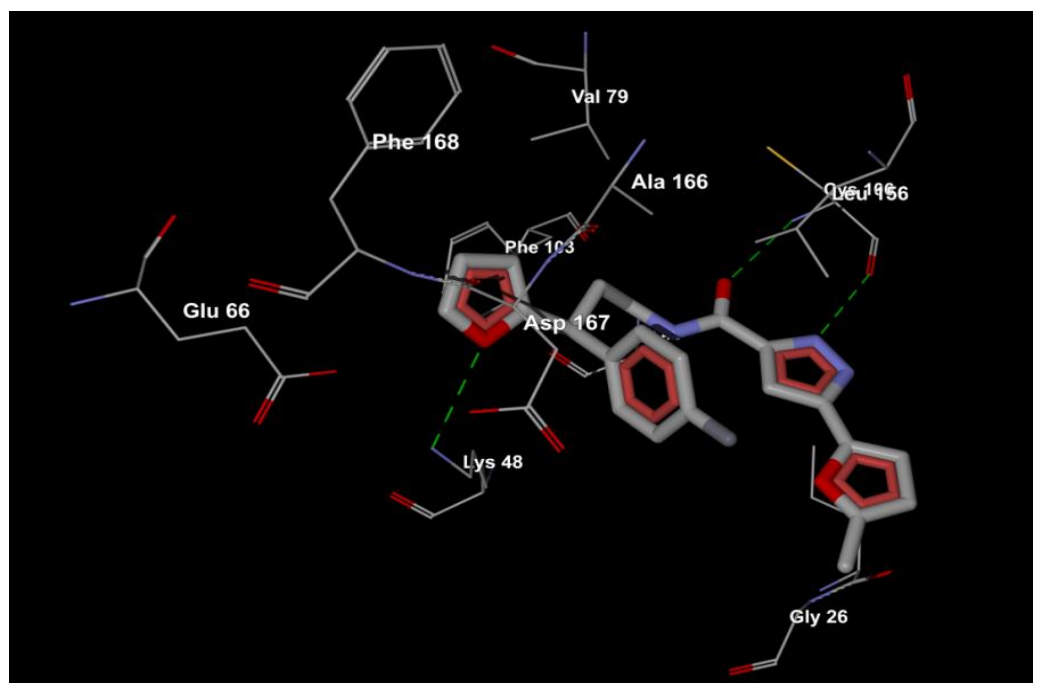

Fig 6: Hydrogen bonding Interactions of ZINC91643349 in cavity of CDK 9. Aminoacids involved in hydrogen bonding interactions are Lys 48, Leu 156 \& Cys 168 


\section{CONCLUSION}

In the present study involving extensive virtual screening methods, we put forth ZINC91643349 as potential CDK9 inhibitor with high affinity and appreciable interaction profile. The typical drug discovery pipeline takes lot of time for lead discovery through high throughput screening or combinatorial screening. Complementing this, virtual screening offers the better understanding of molecular interactions between the drug target and the library compound thereby reducing the time to almost one tenth of the actual. The present study can be put forth for in vitro evaluation for correlate the present study.

\section{REFERENCES}

[1] Jemal A,Bray F,Center MM,Ferlay J, Ward E,Forman D. Global cancer statistics. CA: A Cancer Journal for Clinicians. 2011, 61(2),69-90.

[2] Suresh Gudala, Uzma Khan, Niteesh Kanungo, Srinivas Bandaru, Tajamul Hussain, MS Parihar, Anuraj Nayarisseri, Hema Prasad Mundluru. Identification and Pharmacological Analysis of High Efficacy Small Molecule Inhibitors of EGF-EGFR Interactions in Clinical Treatment of Non-Small Cell Lung Carcinoma: a Computational Approach. Asian Pacific Journal of Cancer Prevention:2015, 16(18), 8191- 8196.

[3] Anand P, Kunnumakkara AB, Kunnumakara AB, Sundaram C, Harikumar KB, Tharakan ST, Lai OS, Sung $\mathrm{B}$, Aggarwal BB.Cancer is a preventable disease that requires major lifestyle changes. Pharm. Res.2008, 25 (9): 2097-2116.

[4] Sherr, Charles J. Cancer cell cycles. Science 1996, 27(4), 5293, 1672-1677.

[5] Campisi, Judith. Cellular senescence as a tumorsuppressor mechanism. Trends in cell biology, 2001, (11) S27-S31.

[6] MacLachlan, Timothy K., Nianli Sang, and Antonio Giordano. Cyclins, cyclin-dependent kinases and cdk inhibitors: implications in cell cycle control and cancer. Critical Reviewsin Eukaryotic Gene Expression.1995, (5), 127-156.

[7] Malumbres, Marcos, and Mariano Barbacid. Mammalian cyclin-dependent kinases. Trends in Biochemical Sciences.2005, 30, 11, 630-641.

[8] Bruyère, Céline, and Laurent Meijer. Targeting cyclindependent kinases in anti-neoplastic therapy. Current Opinion in Cell Biology.2013, 25,(6), 772-779.

[9] Canduri, F., Peres, P. C., Caceres, R. A., de Azevedo, J., and Filgueira, W. CDK9 a potential target for drug development. Medicinal Chemistry. 2008, 4(3), 210-218.

[10] Liu, Xiangrui, Shenhua Shi, Frankie Lam, Chris Pepper, Peter M. Fischer, and ShudongWang. CDKI-71, a novel CDK9 inhibitor, is preferentially cytotoxic to cancer cells compared to flavopiridol. International Journal of Cancer. 2012, 130(5), 1216-1226.

[11] Baumli, S., Lolli, G., Lowe, E. D., Troiani, S., Rusconi, L., Bullock, A. N., and Johnson, L. N. The structure of PTEFb (CDK9/cyclin T1), its complex with flavopiridol and regulation by phosphorylation. The EMBO journal,2008,27 (13), 1907-1918.

[12] Ravi Kumar Kurapati, Archana Giri and Rama Rao Nadendla. Cross Docking as a method to select CDK-9 protein target for virtual screening studies. International Journal of Computational Bioinformatics and In Silico Modeling 2013, 2(6): 275-277.

[13] Shudong Wang, G.Griffiths, CA Midgley, A L Barnett, M Cooper, JGrabarek, L Ingram, W Jackson, G Kontopidis, J Steven, I Stuart, MP Thomas, DIZheleva, DP Lane, RC Jackson, David M Glover, D GBlake, PM Fischer. Discovery and characterization of 2-anilino-4(thiazol-5-yl) pyrimidine transcriptional CDK inhibitors as anticancer agents. Chemistry \&Biology. 2010,17,(10): 1111-1121.

[14] Lukasik, Pawel M., SElabar, F Lam, Hao Shao, X Liu, Abdullah Y. Abbas, and Shudong Wang. Synthesis and biological evaluation of imidazol [4, 5-b] pyridine and 4heteroaryl-pyrimidine derivatives as anti-cancer agents. E J of Medicinal Chemistry 2012.57, 311-22.

[15] Lipinski CA. Drug-like properties and the causes of poor solubility and poor permeability. J PharmacolToxicol Methods.2000, (44), 235-249.

[16] Irwin JJ., and Shoichet, B. K. Zinc-a free database of commercially available compounds for virtual screening. Journal of Chemical Information And Modeling,2005, 45(1),177-182.

[17] Arash Boroumand Nasr,Deepika Ponnala, Someshwar Rao Sagurthi, Ramesh Kumar Kattamuri,Vijaya Kumar Marri, Suresh Gudala, Chandana Lakkaraju, Srinivas Bandaru, and Anuraj Nayarisseri (2015). "Molecular Docking studies of FKBP12-mTOR inhibitors using binding predictions. Bioinformation,2015,11(6), 307315 .

[18] Patidar K, Deshmukh A, Bandaru S, Lakkaraju C, Girdhar A, Vr G, Banerjee T, Nayarisseri A, Singh SK. Virtual Screening Approaches in Identification of Bioactive Compounds Akin to Delphinidin as Potential HER2 Inhibitors for the Treatment of Breast Cancer. Asian Pacific Journal of Cancer Prevention. 2016, 17(4), 2291-2295.

[19] Validation of Quantitative Structure-Activity Relationship (QSAR) Model for Photosensitizer Activity Prediction Neni Frimayanti, Mun Li Yam, Hong Boon Lee, Rozana Othman, Sharifuddin M. Zain and Noorsaadah Abd. Rahman, TSAR, Oxford Molecular, Ltd. Oxford, UK version 3.3. Int. J. Mol. Sci. 2011, (12), 8626-8644. 